\title{
Amputation rate following tibia fractures with associated popliteal artery injuries
}

\author{
Dr MA Roussot ${ }^{1} \mathrm{MBChB}, \mathrm{MPhil}($ Sports and Exercise Medicine) \\ Dr M Held ${ }^{1}$ MBChB, MMed, FC Orth (SA) \\ Dr M Laubscher ${ }^{1}$ MBChB, MMed, FC Orth (SA) \\ Prof AJ Nicol ${ }^{2}$ MBChB, PhD, FCS (SA) \\ Prof PH Navsaria ${ }^{2}$ MBChB, MMed, FCS (SA) \\ A/Prof SJL Roche ${ }^{1} \mathrm{MBChB}$, FC Orth (SA) \\ Dr S Maqungo ${ }^{1}$ MBChB, MMed, FC Orth (SA) \\ ${ }^{1}$ Division of Orthopaedic Surgery, Groote Schuur Hospital \\ ${ }^{2}$ Trauma Centre, Groote Schuur Hospital
}

Presented in part at the South African Orthopaedic Association Congress in Sun City, South Africa, September 2013; and selected for representation at the 'Best of the SAOA Congress',

Cape Town, South Africa October 2013

\author{
Correspondence: \\ Dr Mark Roussot \\ Division of Orthopaedic Surgery \\ H49 Old Main Building \\ Groote Schuur Hospital \\ South Africa \\ Cell: 0824992744 \\ Fax: 0214472709 \\ Email: markroussot@gmail.com
}

\begin{abstract}
Background: Patients with fractures or dislocation about the knee are at increased risk of vascular injury and subsequent limb loss. Our objectives were to: a) determine the amputation rate; and b) identify risk factors in patients with proximal tibial and diaphyseal fractures and associated popliteal artery injuries.

Methods: We conducted a retrospective case-control study of 30 patients with popliteal artery injuries with ipsilateral tibia fractures at a level 1 trauma centre. Primary and delayed amputation rates were determined. Risk factors tested for significance (Fischer's Exact) included: mechanism of injury, limb viability, compartment syndrome, fracture pattern, surgical sequence, and time delay from injury or presentation to revascularisation.

Results: Primary amputation was performed in seven and delayed in ten patients (overall rate 57\%). The 'miserable triad' of a proximal tibia fracture (OTA 41) with signs of threatened viability, and delay to revascularisation $\geq 6$ hours from injury or $\geq 2$ hours from presentation was predictive of amputation ( $p=0.036$ and $p=0.018$ respectively), and almost quadrupled the amputation rate.

Conclusions: We should aim to intervene within 6 hours following injury or 2 hours following presentation to reduce the risk of amputation. This provides a target for trauma teams even with uncertain time of injury.
\end{abstract}

Key words: vascular injury, tibia fracture, amputation

http:/ / dx.doi.org/10.17159/2309-8309/2016/v15n3a4

\section{Introduction}

Vascular injury following extremity trauma is uncommon with a reported incidence of less than $1 \% \%^{1-5}$ however, patients with fractures and dislocations about the knee represent a subgroup of individuals that are at increased risk. ${ }^{1,6}$ Popliteal vascular trauma carries the highest risk of limb loss of any peripheral vascular injury ${ }^{7-9}$ with amputation rates reported between $11 \%$ and $28 \%$ for penetrating and blunt trauma respectively. ${ }^{6}$

Although a variety of scoring systems have been developed and evaluated to assist in the decision of limb salvage versus amputation for major extremity trauma, shortcomings with respect to sensitivity, specificity, subjectivity and failure to predict functional outcome have repeatedly been demonstrated. ${ }^{10-13}$ Delay to revascularisation, however, has frequently been associated with poor outcome. ${ }^{4,14-16}$ 
Our primary objective was to determine the amputation rate in patients with proximal tibial and diaphyseal fractures and associated popliteal artery injuries presenting to a level 1 trauma unit draining a large geographical region. Our secondary objective was to evaluate risk factors for amputation. We hypothesised that a delay to the operating room of 6 hours or more from the time of injury places these patients at increased risk of limb loss.

\section{Patients and methods}

A retrospective analysis was performed on 31 consecutive patients with tibia fractures and confirmed popliteal artery injuries admitted through a level 1 trauma unit from 1 January 1999 to 31 December 2010. Popliteal vascular injury was confirmed by angiography or intra-operatively. The medical records and radiological investigations were analysed in terms of:

- Patient demographics (age, gender)

- Date and time of injury, presentation to the trauma unit and surgical intervention

- Injury data - mechanism of injury, classification of skeletal and vascular injury

- Surgical sequence of revascularisation and external fixation

- Limb viability on presentation

- Associated injuries

- Amputation or limb salvage as the final outcome.

Tibia fractures were described in accordance with the Orthopaedic Trauma Association (OTA) Classification (Table I). ${ }^{17} \mathrm{Limb}$ viability was graded in accordance with the Rutherford classification (Table II). ${ }^{18}$ Primary amputation was defined as ablation of the limb at the time of the first operative procedure without an attempt at limb salvage. Delayed amputation was defined as ablation of the limb following an initial attempt at limb salvage. Risk factors analysed and tested for significance with the Fischer's Exact Test were mechanism of injury, clinical signs of threatened viability (Rutherford grading), compartment syndrome, fracture pattern, surgical sequence (external fixation prior to revascularisation or vice versa), delay from injury to operating room (OR) of $\geq 6$ hours, and delay from admission to OR of $\geq 2$ hours.

\section{Exclusion criteria:}

- Traumatic amputation

- Knee dislocations and fracture-dislocations

- Vascular injury proximal to adductor hiatus or distal to the trifurcation of the popliteal artery.

\section{Results}

Thirty-one patients with tibia fractures and popliteal artery injuries were seen at our Trauma Unit from 1 January 1999 to 31 December 2010. One patient was excluded because of missing medical records, leaving 30 patients for analysis: 22 males with a median age of 29 years (range 15-63 years), and eight females with a median age of 28 years (range $17-48$ years). The average length of stay in hospital for the study group was 23 days (5-65 days) and the mean duration of follow-up after discharge from hospital was 8.8 months (1-36.5 months). Three patients were transferred to peripheral hospitals, one patient died in the intensive care unit with multi-organ failure and three patients were lost to follow-up resulting in a follow-up rate of $89 \%$ (23 patients, $\mathrm{N}=26$ ).

\begin{tabular}{|c|c|c|}
\hline Anatomical region & Group & Fracture pattern \\
\hline \multirow{3}{*}{41 (proximal) } & A & Extra-articular \\
\hline & B & Partial articular \\
\hline & $\mathrm{C}$ & Complete articular \\
\hline \multirow{3}{*}{42 (diaphyseal) } & A & Simple \\
\hline & B & Wedge \\
\hline & C & Complex \\
\hline \multirow{3}{*}{43 (distal) } & A & Extra-articular \\
\hline & B & Partial articular \\
\hline & C & Complete articular \\
\hline
\end{tabular}

Table II: Rutherford Classification of limb viability ${ }^{18}$

\begin{tabular}{|c|c|}
\hline Grade & Description \\
\hline I & Viable \\
IIa & $\begin{array}{c}\text { Marginally threatened or salvageable } \\
\text { if promptly treated }\end{array}$ \\
\hline IIb & $\begin{array}{c}\text { Immediately threatened or salvageable } \\
\text { with immediate revascularisation }\end{array}$ \\
\hline III & Unsalvageable \\
\hline
\end{tabular}

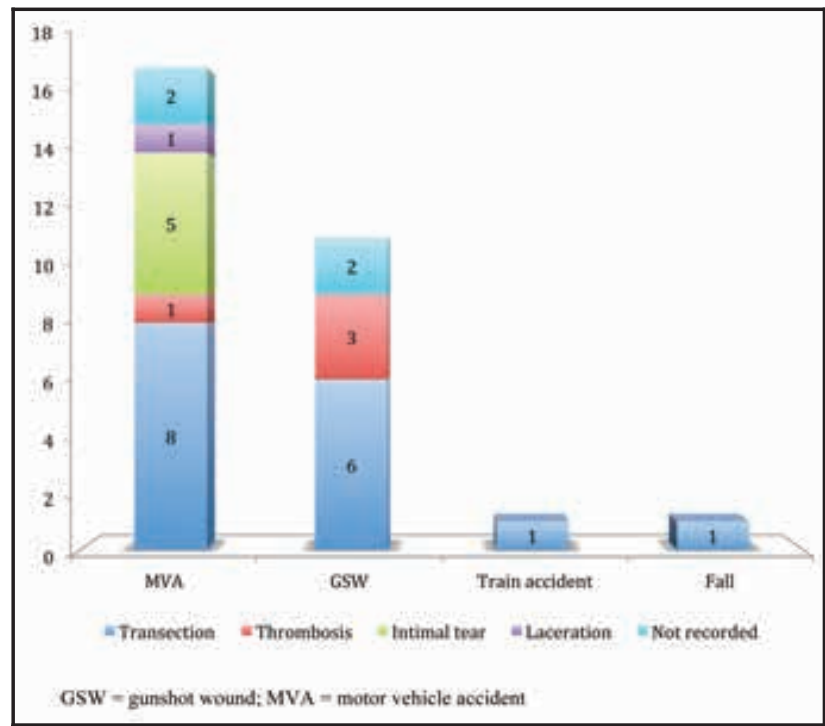

Figure 1. Mechanism of injury and type of arterial injury 
The mechanisms of injury (Figure 1) included 17 motor vehicle accidents (MVAs), 11 gunshot wounds (GSWs), a train accident, and a fall from a height. Associated injuries occurred in 21 patients, and included pelvic fractures in five patients, other long bone fractures in five patients, blunt chest trauma in four patients, head injury in four patients, and blunt abdominal trauma in three patients.

The initial assessment in casualty revealed non-viability (Rutherford III) of the limb in three patients, immediately threatened (Rutherford $\mathrm{IIb}$ ) in 16 patients, and marginally threatened (Rutherford IIa) in six patients. Compartment syndrome was diagnosed clinically in ten patients. An angiogram was performed on 26 patients, ten in the emergency room, ten in the radiology suite, and six were performed on the operating table. The four patients in whom angiography was not performed underwent immediate surgical exploration upon which the clinical diagnosis was confirmed.

Nineteen patients presented with OTA type 41 fractures $(41 \mathrm{a}=8,41 \mathrm{~b}=2,41 \mathrm{C}=9)$ and seven patients presented with OTA type 42 fractures $(42 b=3,42 c=4)$. Images were missing for four patients.

Popliteal artery transection was found in 16 patients, intimal tears in five patients, thrombosis in four patients, partial laceration in one patient, and in four patients findings were not recorded (Figure 1). No significant difference was found in terms of the type of arterial injury (i.e. transection, thrombosis, intimal tear or laceration) relative to the mechanism of injury. The arterial injury was repaired with reverse saphenous vein graft in 17 patients, primary repair in four patients, and polytetrafluoroethylene (PTFE) in two patients. Fasciotomy was performed in 26 patients, ten therapeutically and 16 prophylactically. Five patients underwent primary amputation immediately after fasciotomy as the limb was deemed to be unsalvageable.

Primary amputation was performed in seven patients, three of whom presented with non-viable limbs and four of whom were assessed to have a non-viable limb in the operating room after attempted fasciotomy (Table III). Delayed amputation was performed in ten patients after a mean of eight days, resulting in a total amputation rate of $57 \%$ (17 patients, $N=30$ ). Reported reasons for delayed amputation included graft failure in four patients, the development of compartment syndrome in two patients for whom prophylactic fasciotomy was not performed, and massive soft tissue injury in two patients.

The surgical sequence was recorded in 23 patients who underwent limb salvage. Thirteen patients were explored prior to external fixation (seven went on to amputation) and ten patients underwent external fixation prior to exploration (six went on to amputation). This had no significant impact on the amputation rate.

The median delay from injury to presentation (Table IV) was 5 hours (range $1-144$ hours, $N=27$ ); median delay from presentation to OR was 4 hours (range 1-47 hours, $N=30$ ); and median delay from injury to OR was 10 hours (range 4-150 hours, $N=27$ ).
Analysis of the risk factors (namely mechanism of injury, initial assessment of viability, presence of compartment syndrome, fracture pattern, and delay to intervention) revealed that each variable was associated with higher amputation rates, but none was individually predictive of amputation with statistical significance (Table V). However, patients with a proximal tibia fracture (OTA 41), clinical signs of threatened viability, and a delay from injury to the OR of $\geq 6$ hours showed a significantly higher amputation rate of $67 \%$ versus $18 \%(p=0.036)$. Similarly patients with a proximal tibia fracture (OTA 41), clinical signs of threatened viability and a delay from presentation to the OR of $\geq 2$ hours showed a significantly higher amputation rate of $69 \%$ versus $18 \%(p=0.018)$.

\section{Discussion}

More than half of the patients presenting with proximal tibia fractures with associated popliteal artery injuries underwent amputation despite attempts at limb salvage. Notably, the 'miserable triad' of a proximal tibia fracture with clinical signs of threatened viability and a delay to OR of $\geq 6$ hours from injury or $\geq 2$ hours from presentation resulted in a statistically significant increased risk of limb loss, suggesting that every attempt should be made to intervene with this subgroup of patients within 6 hours of injury or 2 hours of presentation to hospital in order to improve outcome. This finding provides trauma teams with a target even if the exact time of injury is uncertain.

The reported amputation rate in patients with popliteal artery injuries varies greatly among authors, averaging $28 \%$ for blunt and $11 \%$ for penetrating trauma, but has been reported as high as $71 \% .^{6,19}$ The amputation rate in the present study was $57 \%$, which included seven primary and ten delayed amputations. This is greater than that reported in a series of 136 popliteal artery injuries conducted at the same institution, which demonstrated an overall amputation rate of $37.5 \% .^{14}$

\begin{tabular}{|c|c|c|}
\hline & $\begin{array}{c}\text { Number of } \\
\text { patients }\end{array}$ & $\begin{array}{c}\% \text { of study } \\
\text { group }(\mathrm{N}=\mathbf{3 0})\end{array}$ \\
\hline Primary amputation & 7 & $23 \%$ \\
\hline Delayed amputation & 10 & $33 \%$ \\
\hline Total amputation & 17 & $57 \%$ \\
\hline
\end{tabular}

\begin{tabular}{|c|c|c|c|}
\hline & $\begin{array}{l}\text { Time from injury } \\
\text { to presentation } \\
\text { (hours) }\end{array}$ & $\begin{array}{l}\text { Time from } \\
\text { presentation } \\
\text { to OR (hours) }\end{array}$ & $\begin{array}{c}\text { Time from } \\
\text { injury to OR } \\
\text { (hours) }\end{array}$ \\
\hline Mean & 10.4 & 8.7 & 19.3 \\
\hline Median & 5.0 & 4.0 & 10.0 \\
\hline Range & $1-144$ & $1-47$ & $4-150$ \\
\hline $\mathrm{N}$ & 27 & 30 & 27 \\
\hline
\end{tabular}




\begin{tabular}{|c|c|c|c|}
\hline & \multicolumn{3}{|c|}{ Amputation } \\
\hline & $\mathbf{N}$ & $\bar{n}$ & $p$-value \\
\hline \multicolumn{4}{|l|}{ Mechanism of injury } \\
\hline MVA & 17 & 11 & \multirow{3}{*}{0.264} \\
\hline GSW & 11 & 6 & \\
\hline Other & 2 & & \\
\hline \multicolumn{4}{|c|}{ Initial assessment of limb viability } \\
\hline Viable & 6 & 2 & \multirow{3}{*}{0.179} \\
\hline Threatened & 21 & 12 & \\
\hline Non-viable & 3 & 3 & \\
\hline \multicolumn{4}{|l|}{ Compartment Syndrome } \\
\hline Present & 10 & 6 & \multirow[t]{2}{*}{0.705} \\
\hline Absent & 20 & 11 & \\
\hline \multicolumn{4}{|l|}{ Fracture pattern (AO) } \\
\hline 41 & 19 & 12 & \multirow{8}{*}{0.190} \\
\hline A & 8 & 5 & \\
\hline B & 2 & 0 & \\
\hline C & 9 & 7 & \\
\hline 42 & 7 & 2 & \\
\hline A & 0 & 0 & \\
\hline B & 3 & 1 & \\
\hline $\mathrm{C}$ & 4 & 1 & \\
\hline \multicolumn{4}{|l|}{ Timing of stabilisation } \\
\hline Exploration first & 13 & 7 & \multirow[t]{2}{*}{1.000} \\
\hline Exploration after ExFix & 10 & 6 & \\
\hline \multicolumn{3}{|l|}{ Delay from injury to OR } & \multirow{3}{*}{0.294} \\
\hline$\geq 6$ hours & 23 & 14 & \\
\hline$<6$ hours & 4 & 1 & \\
\hline \multicolumn{3}{|c|}{ Delay from admission to $O R$} & \multirow{3}{*}{0.360} \\
\hline$\geq 2$ hours & 24 & 15 & \\
\hline$<2$ hours & 6 & 2 & \\
\hline \multicolumn{3}{|c|}{ AO $41+$ Threatened + delay from injury to OR $\geq 6$ hours } & \multirow{3}{*}{0.036} \\
\hline Yes & 12 & 8 & \\
\hline No & 11 & 2 & \\
\hline \multicolumn{3}{|c|}{ AO $41+$ Threatened + delay from admission to $\mathrm{OR} \geq 2$ hour } & \multirow{3}{*}{0.018} \\
\hline Yes & 13 & 9 & \\
\hline No & 11 & 2 & \\
\hline
\end{tabular}

The higher risk of amputation in patients with complex extremity trauma involving popliteal vascular injury combined with skeletal trauma, in comparison to either injury in isolation, is well documented; $;, 7,8,15,20,21$ however, the reasons for this are not clear. Delay in recognition due to the presence of multiple injuries, inadequate soft tissue coverage, and the high incidence of compartment syndrome are factors that may contribute to higher amputation rates in this setting. ${ }^{6-8}$ The rarity of major vascular injuries in orthopaedic trauma and subsequent lack of experience in managing them has also been postulated to impact on outcome. ${ }^{3}$ In this study only 31 patients with tibial fractures and popliteal artery injuries were seen at our level 1 trauma unit over an 11-year period.
The temporal relationship between ischaemic time and amputation rate is supported by clinical and experimental studies $^{6,22,23}$ and generally accepted as one of the most important factors in determining the ultimate fate of a limb with vascular injury; ${ }^{4,6,8,15}$ hence, early intervention is associated with improved prognosis. ${ }^{3,8,15}$ However, the definition of 'early' differs among authors, some of whom have challenged the traditionally recommended goal of injury to OR time of less than 6 hours and have even demonstrated the benefit of vascular reconstruction in patients with a delay of more than 12 hours. ${ }^{3}$ In the present study the majority of patients reached OR 6 hours or more following injury. This may be explained in part by delays to presentation at the trauma unit, but are also due to delays to the OR once in the trauma unit. The reasons for delay need to be evaluated in this setting and cannot be entirely attributed to the inclusion of rural drainage areas alone. The initial clinical assessment of threatened viability was associated with increased risk of limb loss in this study group, although not with statistical significance. This association has been highlighted as an independent predictor of outcome in previous studies. ${ }^{6,8}$

The finding that the majority of patients in this study group $(70 \%)$ were polytrauma victims emphasises the need for a multidisciplinary team approach, prioritising diagnostic and therapeutic procedures. Identifying vascular injury in this context requires extra clinical vigilance, a high index of suspicion, liberal use of Doppler ultrasound and appropriate use of angiography. ${ }^{6}$ On-table angiography has been shown to prevent delays associated with formal angiography, ${ }^{3,9}$ which should be reserved for patients with reasonable distal perfusion in whom the diagnosis of arterial injury is in doubt..$^{24}$

The sequence of revascularisation and external fixation in this study group appeared to have no association with limb loss. While the timing of stabilisation of fractures in the context of vascular injury is contentious,,$^{1,2,6}$ a meta-analysis has demonstrated no difference in the amputation rates in patients undergoing vascular repair prior to stabilisation versus those undergoing stabilisation prior to vascular repair. ${ }^{2}$ At our institution the fracture is stabilised with external fixation prior to vascular repair unless the surgical team assesses that the limb is in need of immediate revascularisation. In this case, a shunt may be introduced, and then manipulation and external fixation performed, followed by definitive vascular repair. This approach is regarded as safe and is common practice. ${ }^{6,89,23}$ We further recommend that the surgical team prioritises revascularisation prior to external fixation if external fixation is likely to proceed beyond the target of 6 hours post injury or 2 hours post presentation to the trauma unit. Owing to the difficulty in accurate post-operative clinical assessment of compartment pressures and the high incidence of compartment syndrome following revascularisation, we strongly recommend that prophylactic fasciotomy is performed following revascularisation in all of these patients, which is supported by previous studies. ${ }^{3,6,14,22,25}$ 
Seven patients had tibial diaphyseal fractures and popliteal artery injuries. One was related to a gunshot wound with the bullet tract involving the vessel. The remaining six were polytrauma victims related to motor vehicle accidents and the fractures were all located in the proximal diaphysis. While it would seem intuitive that diaphyseal fractures are more likely to cause vascular injury distal to the trifurcation, it is recognised that this does not preclude more proximal vascular injuries. ${ }^{6}$ The movement of the popliteal vessels is restricted inferiorly by the fibrous soleus arch, placing the artery at risk in the context of high energy trauma that results in soft tissue tension or disruption at or below this level. ${ }^{6}$

Despite advances in trauma care the outcome of lower limb trauma in the presence of popliteal arterial injury still tends to be poor. ${ }^{3,6,7,9}$ Resource utilisation is high owing to prolonged hospital stays and numerous visits to the OR, 12,13 and the choice between primary amputation and limb salvage remains challenging. This should provide the impetus to intervene timeously.

To our knowledge, this is the largest series of proximal tibia fractures with associated popliteal artery injuries in a resource-limited level 1 trauma centre. Follow-up was performed to obtain enough information for the primary outcome (amputation or limb salvage); however, the assessment of functional outcome and patient satisfaction through long-term follow-up was not conducted.

\section{Conclusions}

Tibia fractures with associated popliteal artery injuries have an amputation rate of $57 \%$. The subset of patients with the 'miserable triad' of a proximal tibia fracture, clinical signs of threatened viability and a delay to OR of $\geq 6$ hours from injury or $\geq 2$ hours from admission have a significantly increased risk of amputation (nearly four-fold). The authors recommend that trauma teams aim to intervene in these patients within 6 hours of injury or 2 hours of presentation.

\section{Compliance with Ethics Guidelines}

Conflicts of Interest and Source of Funding: None

Ethics approval was obtained through the University of Cape Town Human Research Ethics Committee (HREC Ref: 413/2013)

No benefits of any form have been received from a commercial party related directly or indirectly to the subject of this article.

\section{References}

1. Halvorson JJ, Anz A, Langfitt M, et al. Vascular injury associated with extremity trauma: initial diagnosis and management. J Am Acad Orthop Surg 2011 Aug;19(8):495-504

2. Fowler J, Macintyre N, Rehman S, et al. The importance of surgical sequence in the treatment of lower extremity injuries with concomitant vascular injury: A meta-analysis. Injury. 2009 Jan;40(1):72-76.

3. Allen MJ, Nash JR, Ioannidies TT, Bell PRF. Major vascular injuries associated with orthopaedic injuries to the lower limb. Ann R Coll Surg Eng 1984;66:101-104.
4. Howard PW, Makin GS. Lower limb fractures with associated vascular injury. J Bone Joint Surg Br. 1990 Jan;72(1):116-20.

5. Porter MF. Arterial injuries in an accident unit. Br J Surg. 1967 Feb;54(2):100-105.

6. Frykberg ER. Popliteal vascular injuries. Surg Clin North Am 2002;82:67-89.

7. Mullenix PS, Steele SR, Andersen CA, Starnes BW, Salim A, Martin MJ. Limb salvage and outcomes among patients with traumatic popliteal vascular injury: an analysis of the National Trauma Data Bank. J Vasc Surg 2006 Jul;44(1):94-100.

8. Pourzand A, Fakhri BA, Azhough R, Hassanzadeh MA, Hashemzadeh S, Bayat AM. Management of high-risk popliteal vascular blunt trauma: clinical experience with 62 cases. Vasc Health Risk Manag 2010 Aug 9;6:613-18.

9. Subasi M, Cakir O, Kesemenli C, Arslan H, Necmioglu S, Eren N. Popliteal artery injuries associated with fractures and dislocations about the knee. Acta Orthop Belg 2001 Jun;67(3):259-66.

10. Dirshl DR, Dahners LE. The mangled extremity: when should it be amputated? J Am Acad Orthop Surg 1996;4:182-190.

11. Ly TV, Travison TG, Castillo RC, Bosse MJ, MacKenzie EJ, LEAP Study Group. Ability of lower-extremity injury severity scores to predict functional outcome after limb salvage. J Bone Joint Surg Am 2008;90:1738-43.

12. Simmons JD, Gunter JW 3rd, Schmieg RE Jr, Manley JD, Rushton FW Jr, Porter JM, Mitchell ME. Popliteal artery injuries in an urban trauma center with a rural catchment area: do delays in definitive treatment affect amputation? Am Surg 2011 Nov;77(11):1521-25.

13. Bosse MJ, MacKenzie EJ, Kellam JF, Burgess AR, Webb LX, Swiontkowski MF, Sanders RW, Jones AL, McAndrew MP, Patterson $\mathrm{BM}, \mathrm{McCarthy} \mathrm{ML}$, Cyril JK. A prospective evaluation of the clinical utility of the lower-extremity injury-severity scores. J Bone Joint Surg Am. 2001 Jan;83-A(1):3-14.

14. Banderker MA, Navsaria PH, Edu S, Bekker W, Nicol AJ, Naidoo N. Civilian popliteal artery injuries. S Afr J Surg. 2012 Nov 12;50(4):11923.

15. McCabe CJ, Ferguson CM, Ottinger LW. Improved limb salvage in popliteal artery injuries. J Trauma. 1983 Nov;23(11):982-85.

16. Pretre R, Bruschweiler I, Rossier J, et al. Lower limb trauma with injury to the popliteal vessels. J Trauma 1996;40:595-601.

17. Marsh JL, Slongo TF, Agel J, et al. Fracture and Dislocation Classification Compendium - 2007: Orthopaedic Trauma Association Classification, Database and Outcomes Committee. J Orthop Trauma. 2007;21 Supplement 10 pp: S1-S163.

18. Rutherford RB, Baker JD, Ernst C, et al. Recommended standards for reports dealing with lower extremity ischemia: revised version. $J$ Vasc Surg. 1997 Sep;26(3):517-38.

19. Conkle DM, Richie RE, Sawyers JL, et al. Surgical treatment of popliteal artery injuries. Arch Surg 1975;110:1351-54.

20. Applebaum R, Yellin AE, Weaver FA, et al. Role of routine arteriography in blunt lower extremity trauma. Am J Surg 1990;160:221-25.

21. Downs AR, MacDonald P. Popliteal artery injuries: civilian experience with sixty-three patients during a twenty-four year period (1960 through 1984). J Vasc Surg. 1986 Jul;4(1):55-62.

22. DeBakey ME, Simeone FA. Battle injuries of the arteries in World War II; an analysis of 2,471 cases. Ann Surg. 1946 Apr;123:534-79.

23. Miller $\mathrm{HH}$, Welch CS. Quantitative studies on the time factor in arterial injuries. Ann Surg. 1949 Sep;130(3):428-38.

24. Yahya MM, Mwipatayi BP, Abbas M, Rao S. Popliteal artery injury: Royal Perth experience and literature review. ANZ J Surg 2005;75:882-86.

25. Hafez HM, Woolgar J, Robbs JV. Lower extremity arterial injury: results of 550 cases and review of risk factors associated with limb loss. J Vasc Surg. 2001 Jun;33(6):1212-19.

This article is also available online on the SAOA website (www.saoa.org.za) and the SciELO website (www.scielo.org.za). Follow the directions on the Contents page of this journal to access it. 